\title{
Social support networks, instant messaging, and gender equity in refugee education
}

\section{Citation}

Dahya, Negin, Dryden-Peterson, Sarah, Douhaibi, Daci and Arvisais, Oliver. 2019. Social support networks, instant messaging, and gender equity in refugee education. Information, communication \& Society.

\section{Permanent link}

http://nrs.harvard.edu/urn-3:HUL.InstRepos:38595192

\section{Terms of Use}

This article was downloaded from Harvard University's DASH repository, and is made available under the terms and conditions applicable to Open Access Policy Articles, as set forth at http:// nrs.harvard.edu/urn-3:HUL.InstRepos:dash.current.terms-of-use\#OAP

\section{Share Your Story}

The Harvard community has made this article openly available.

Please share how this access benefits you. Submit a story.

Accessibility 


\title{
Social support networks, instant messaging, and gender equity in refugee education
}

\author{
*Negin Dahya, University of Washington | ndahya@uw.edu \\ Sarah Dryden-Peterson, Harvard Graduate School of Education \\ Dacia Douhaibi, York University
}

Olivier Arvisais, Université du Québec à Montréal

\begin{abstract}
Author Bios
Negin Dahya is an Assistant Professor at the University of Washington Information School (UW iSchool), Seattle, Washington. Dahya's research is focused on understanding the social and cultural conditions in which technology is created and used, with a focus on digital and social media in educational settings. Her research in refugee education and technology has centered on applying sociotechnical theory to understand the role of mobile phones and social media to support teaching and learning among refugees, particularly for those pursuing and enrolled in post-secondary training and higher education. Dahya is a co-convener for the Inter-Network Agency in Emergencies Technology Task Team.

Sarah Dryden-Peterson is an Associate Professor of Education at the Harvard Graduate School of Education. Her research focuses on education in armed conflict and the ways in which learning, pedagogies, and relationships may alter trajectories of conflict for nation-states and individuals. She has been recognized as a Social Sciences and Humanities Research Council of Canada Postdoctoral Fellow, a National Academy of Education/ Spencer Foundation Postdoctoral Fellow, and a Fulbright Scholar.
\end{abstract}

Dacia Douhaibi is a doctoral candidate, researcher, and educator currently positioned at York University in Toronto, Canada. Dacia holds an MA in International Affairs from the Norman Paterson School of International Affairs at Carleton University and completed a Bachelor of Arts in Anthropology at the University of Victoria. Dacia has worked on several community development projects in Asia, Central America, and Africa.

Olivier Arvisais is a professor at the Faculty of Education of the Université du Québec à Montréal (UQAM). He is the scientific director of the Canadian Observatory on Humanitarian Crises and Assistance. Professor Arvisais is also co-chair of the scientific committee of the UNESCO Chair in Curriculum Development. He is a specialist in education in emergencies. His research focuses on educational initiatives in refugee camps, child protection through socioemotional learning and education under armed groups or totalitarian proto-states. 


\title{
Social Support Networks, Instant Messaging, and Gender Equity in Refugee Education
}

\begin{abstract}
This paper addresses the role of instant messaging chat groups to support teacher training and gender equity initiatives in Kenyan refugee camps. Our findings are based on survey data with refugee teachers in Dadaab and Kakuma refugee camps (n=203), group interviews with refugee teachers in Kakuma $(n=21)$, and interviews with international instructors of teacher training programs in Nairobi, Toronto, and Vancouver $(n=14)$. In our analysis, we apply amplification theory, feminist science and technology studies paradigms, and considerations of transnational approaches to understand the use of instant messaging among refugee teacher communities. Our framework explores how social and cultural norms are amplified through transnational text and instant messaging related to teacher training and in support of gender equity. Peer-to-peer group chats draw on transnational learning opportunities and expand these engagements through group chats between men and women refugee teachers across camps as well as through community engagement about gender equity initiatives in education. International instructors identify both value and hesitation in navigating the quantity and content of these communications, such as learning more about refugee teachers' daily lives in the camps and concern about following and managing the amount of communication that can ensue over chat groups. Our work has practical implications for transnational teacher training programs in refugee camps, illuminates how mobile technology and chat groups allow women and men in the community to engage and support girls' education, and questions how text messaging affects the lived and day-to-day experiences of women refugee teachers.
\end{abstract}




\section{Key Words}

Refugee education, Feminist STS, Transnationalism, Instant Messaging, post-secondary education, gender equity

\section{Introduction: Refugee camps, teacher training and gender equity in Kenya}

Jonas is a refugee who teaches in an all-girls secondary school in the Kakuma Refugee Camps in northeast Kenya, where teachers at the secondary level are predominantly men. He started teaching in 2015 with no training, except that provided for teachers already working in schools in the camps by the nonprofit organizations managing education in the region (in-service teacher training). Jonas explained that when he first walked into the classroom he was confused to see an all-girl environment, and he was 'really afraid to manage them.' He described the value of inservice teacher training and peer networks that communicate over a group chat using the application, WhatsApp:

You find most learners in the camp, especially refugees, they have been raised in this hostile environment. Some of them are traumatized. Dealing with them at some point is always hard. So ... if a learner is indiscipline [acting out] in school, instead of giving a punishment which could be heavy on her, actually we could find that the best way [might become clear if] we could discuss it in the [WhatsApp] group. [Through the WhatsApp group, I learned] We could visit her family and talk to her parents and discuss her behavior in school... (Jonas, Group Interview 1, April 2016).

In this paper, we explore how mobile phones and social networks support gender equity initiatives among men and women teachers in Kenyan refugee camps where girls' enrollment 
and completion of primary and secondary school is low, and where there are few women refugee teachers.

The Dadaab and Kakuma refugee camps are protracted refugee contexts where many refugees have lived for decades. They are some of the largest refugee camps in the world. In both locations, there are overcrowded classrooms, under-trained teachers, deeply-rooted patriarchy, and consequent inequities in education access and achievement for girls. Within each camp, there are four to six sub-communities, relatively far from each other, resulting in difficulty communicating and collaborating across schools, long and arduous walks to and from each camp sub-region, and/or the need to find limited and sometimes costly transportation intra-regionally (e.g. bikes, local buses). In both Dadaab and Kakuma, there are higher education and postsecondary teacher training programs that have goals to enhance the education system through better trained teachers and with a focus on girls’ education. These international education efforts are complex, typically involving a nonprofit organization funded internationally, with national headquarters in Nairobi, and with offices in the camps to support enrolment, technology, and class scheduling. Often, as in the cases presented in this paper, the instructors within these programs do not live in the camps and are Kenyan nationals or international community members, such as university faculty from Canada. The instructors sometimes travel to the camps for periods of instruction and additionally work remotely using Learning Management Systems (e.g. Moodle, Blackboard, Canvas) or alternative digital tools such as email or file sharing over mobile phones and tablets. Text and instant messaging are notable aspects of these educational landscapes (Dahya \& Dryden-Peterson, 2017; Dryden-Peterson, Dahya \& Adelman, 2017). Ninety-three percent of refugees have access to some level of digital infrastructure to support internet access and mobile communication. Further, many refugees spend up to a third of 
their limited financial resources ‘staying connected’ (UN High Commission for Refugees, 2016). In this landscape, digital communities may be an asset to teachers and their students to support teacher training, provide digital content, and enhance opportunities for literacy and learning (see Unwin, Weber, Brugha \& Hollow, 2017). Our own previous work has identified a crucial, supportive role that both mobile phones and social networks have in the education of refugees in Kenya, particularly among secondary school graduates who often proceed to become teachers in the camps (see Dahya \& Dryden-Peterson, 2017; Dryden-Peterson et al., 2017). We drew on data collected through in-depth interviews with refugees from Dadaab Refugee Camps pursuing postsecondary education and on survey data from the Somali diaspora to understand the role of transnational networks, including information and communication technology (ICT) and social media. Transnational social networks, mediated by mobile phones and internet-enabled apps like WhatsApp, emerged from preexisting face-to-face relationships established in person in the camps, most notably with other refugee teachers and refugee community members who then migrated elsewhere. These transnational networks informed and supported refugees from Dadaab in pursuing higher education, particularly women (Dahya \& Dryden-Peterson, 2017; DrydenPeterson et al., 2017).

In this research, we examined more deeply the role of text and instant messaging and mobile phones among refugee teacher communities in the two Kenyan refugee camps, Dadaab and Kakuma. In particular, we aimed to understand the nature of transnational communication using mobile phones and messaging applications among refugee teachers in camps and across international instructors not based in the camps. Our work focused on gender equity, considering programs that both target the inclusion of refugee women teachers and teach teachers about gender responsive pedagogy and practice. We define text messaging as Short Messaging Service, 
or SMS, which is available over cellular networks without access to Wi-Fi or purchase of data plans for mobile phones; SMS is also available on more basic phones like flip-phones which are still in use in the camps. Instant messaging includes Wi-Fi or data-enabled messenger applications like Facebook Messenger and WhatsApp Messenger, with the added features and common practices of group communication in group chats.

Throughout this paper, we explore how transnational communication networks impact educational practices and influence cultural norms related to gender equity. Toukan et al. (2017) describe transnationalism as sustained cultural, political, and economic activities, relationships, and practices that reach across national borders. Within this definition, our approach to transnationalism is broad, including among migrant communities and their diasporic networks (e.g. Basch, Schiller, and Blanc, 1994). The breadth also relates to changing social and cultural norms in the face of technologically-mediated and globally-connected people not always from the same community of origin (see Roudometof, 2005). We consider how boundaries and conceptual borders related to education shift using transnationally-connected mobile technology when living within the confined geographic and political settings of refugee camps. Specifically, we explore how transnational social spaces and transnational networks (Roudometof, 2005) manifest through mobile communication related to teacher training; and we consider how transnationalism informed by text and instant messaging influences gender equity.

In this work, we attend to gender equity considering the differential responses of women and men research participants. We also examine the experiences of teachers enrolled in teacher training programs that offer training in gender responsive pedagogy and/or adopt genderinclusive practices in terms of enrolment of women refugee teachers. Finally, we ask pertinent questions about how existing power structures related to women's work and lives are 
destabilized, if at all, in the digital information society in refugee camps (Wajcman, 2006). We find that men are critical to support these gender equity initiatives in a landscape where there are proportionally few women refugee teachers. Where women refugee teachers are present, they too draw on transnational and peer-to-peer communication networks, through IM and group chat, to support their social and academic needs in their teaching training. Peer-to-peer group chats among men and women are structured around actively changing social norms related to girls' and women's educational opportunities. In these ways, this paper highlights transnational and sociotechnical mechanisms for supporting girls' education.

\section{Mobile and networked technology and refugee education}

Research about refugees and technology is rapidly growing across disciplines, including education, communication, and migration studies. For example, Leung (2018) describes how, in the constrained settings of detention centers in Australia, refugees are dependent on information sharing through weak and geographically-distributed social ties mediated by technology. Leung suggests that technology among refugee communities is important to 'maintain their tenuous and fragile relationships with the world outside refugee camps and detention centers' (p. 49). Leung also notes that education initiatives attempting to use technology such as computer labs show that older and often lower-tech strategies can lead to more effective learning outcomes (Leung, 2018, p. 45). Mobile phones as a preexisting technology in the hands of refugees pursuing higher education are a key factor in this landscape.

Existing research and education initiatives suggest that there are opportunities for mobile phones to contribute to the development of teaching and learning practices. For example, in Kakuma Refugee Camps in Kenya, refugee teachers use mobiles to engage in group 
communication at the peer-to-peer level and also with educators globally who offer remote coaching through these instant messaging conversations over WhatsApp (see Mendenhall, Gomez \& Varni, 2018). In Dadaab, where material resources are scarce, collective knowledge and community networks mediated by tools like WhatsApp on mobile phones are essential contributors to education. Boškić et al. (2018) note that mobiles and their relevant applications do not replace face-to-face learning; nor do they address the need for material resources such as private spaces for women to breastfeed near to where teacher training or other post-secondary classes are delivered. Yet mobile technology can be resources in refugee education, as both material and social capital (Dryden-Peterson et al., 2017).

On the one hand, women remain excluded from technology and higher education opportunities in refugee settings. Contributing factors include entrenched patriarchy, manifest as ongoing, unequal distributions of domestic labor and childcare needs, as well as lesser access to technological literacy and training opportunities (Boškić et al., 2018; Dahya \& Dryden-Peterson, 2017; Pimmer, Zelezny-Green, \& Gröhbiel, 2018). On the other hand, women pursuing higher education in Dadaab, for example, use instant messaging chat groups, SMS, and phone calls to create peer social networks that support their education, and they identify these supports as more critical than men do (Dahya \& Dryden-Peterson, 2017). Pimmer et al. (2018) suggest that if women in refugee settings have access and training to participate in digital learning environments, their participation is equal to or exceeds that of peers who are men. Together, these perspectives on the role of technology and mobile phones specifically for girls and women's education make further inquiry into mobile phones and text messaging an important area for research, with clear implications for transnational teacher training and practice in refugee camps. 


\section{Amplification theory, transnational approaches, and feminist STS}

The premise of amplification theory (Toyama, 2011, 2015) is that, in the context of development, technology is not a problem-solver or a 'fixer,' it cannot make up for a lack of human intent or capability, and it cannot dismantle other systemic and institutional structures hindering progress and propelling poverty. Technology can enhance, augment, support, streamline, improve, or worsen existing realities but not recreate them. This approach, where technology is an amplifier of existing social structures, defies popular belief that technology can serve an additive function, deeply changing the context in which it is deployed and used. The function of technology in a development setting is then related to both human intent and capacity, and subject to the power of politics, economics, and education.

We build on amplification theory and consider feminist sociotechnical theory to addresses the mutually shaping relationships between society and technology as they affect gender equity. Witteborn (2018), for example, describes how an Afghani asylum seeker in Germany, Saamiya, volunteered at an Internet Café through a refugee-serving NGO to learn about computer hardware and software. Saamiya’s experience was a source of both pride and pleasure. She also faced social shaming from male peers who she learned found her position and interactions with the public inappropriate. This socially configured disciplinary practice of shaming led to Saamiya leaving her position as a volunteer, which maintained the dominant patriarchal order (p. 26). In this case, neither access nor opportunity to work with technology was enough to influence the social norms and expectations imposed on Saamiya during her migration. 
The development of feminist sociotechnical theory in Western industrialized settings has identified ways in which digital life both helps and hinders equity. This critical lens invites questions about how text and instant messaging in refugee camps interact with existing social norms and power structures, with a focus on the work and daily lives of girls and women (Wajcman, 2006). In this study, we consider feminist approaches to society and technology in relation to the transnational influences that emerge over text and instant messaging, across peer networks in refugee camps, and with international instructors. These axes of communication and education are positioned within existing power structures related to society and culture in the camps and outside of them, and while mobile technologies are not 'fixers' of problems in the camps, we explore how information, knowledge, and culture are built, shared, and exchanged transnationally in ways that impact local refugee camp settings and communities.

In this landscape, we further consider how the material artifacts of mobile phones host and shape social and cultural exchange, influence the day-to-day activities of a community, and inform policies and practices in areas such as education (Ling \& Horst, 2011). For example, having access to mobile communication as part of an in-service teacher training program may enhance expectations to complete or prepare work at home, a previously impossible task due to a lack of resources like notebooks, pens, and electricity. In this paper, we seek to understand what is amplified and how amplification occurs with technology, considering the information and power circulating through transnational teacher training programs and refugee teacher communities as they work towards gender equity.

\section{Research Methods \& Context}


We designed our study as a mixed methods case to investigate the use of text and instant messaging for education in refugee camps. We used concurrent design (Creswell, 2014), conducting qualitative group interviews and a survey simultaneously during a single phase of data collection. We draw on Bartlett and Vavrus' concept of 'multi-scalar' research (2017) to examine the multiple and intersecting scales, or axes, on which actors and practices are embedded. We focus on the vertical and horizontal axes, to illuminate vertical interconnections among locally-situated teachers and nationally- and globally-situated instructors, as well as horizontally across teachers working in refugee camps in Kenya. At local levels, our analysis focuses on teacher practices and, at national and global levels, we focus on the structure and content of teacher training programs and in-service teacher professional development.

There are two teacher training programs included in this study. One of the two programs is only delivered in the Dadaab Refugee Camps and is a university-level teacher training program offering certificates, diplomas, and full degrees, called Borderless Higher Education for Refugees (BHER). University instructors for BHER were from Canada and Kenya and one of the authors worked as an instructor in this program. The second program is a professional development teacher training program with instructors from Kenya and offers periodic training in gender responsive pedagogy and remedial education in both Dadaab and Kakuma, called the Kenya Equity in Education Program (KEEP). Both programs primarily used onsite instruction and adopted various remote learning strategies to support or continue teaching and learning opportunities.

Our guiding research questions are: 
1. How are refugee teachers in camps using text and instant messaging on mobile phones to support their learning and professional development?

2. What is the nature of text-based communication on mobile phones by and between refugee teachers in camps (e.g. topics of discussion, technical specifications of devices, etc.)?

3. What is the nature of the transnational relationship between international instructors and refugee teachers in camps using mobile text and instant messaging?

4. How is gender equity supported in educational settings in refugee camps using text and instant messaging among refugee teachers?

Concurrent data collection using surveys and interviews allowed us to confirm and corroborate our analysis internally. We used surveys to capture specific information about what kind of mobile phones, chat programs, and curricular content teachers used. We developed the survey in consultation with internationally-situated instructors of refugee teachers in Canada and Kenya who worked with BHER and KEEP. We conducted a pilot survey in Dadaab with 50 teachers; we discussed the survey with respondents if/when they had questions as they were filling it out and after. Following this process, we revised the survey and then collected 203 paper survey responses from teachers in Dadaab and Kakuma onsite. We refer to the women and men who completed surveys as 'respondents.' We targeted women refugee teachers resulting in 40/203 women respondents. The majority of our respondents were under 32 years of age (89\%); 44\% were aged between 17 and 25 years old and 45\% between 26 and 32 years old.

Our group interviews with refugee teachers in Kakuma focused on understanding their experiences and perspectives using text and instant messaging as part of their teacher training 
programs. These were audio recorded and resulted in five group discussions with 21 refugee teachers (18 men, 3 women). The nature of group interviews limited our ability to foster rich conversation with the few women who were able to travel to the central nonprofit offices in Kakuma for interviews. Given challenges of washed-out roads and security heavily restricting researcher movement in Dadaab, we secured no interviews with refugee teachers there. There is methodological precedent for using text and instant messaging to conduct research interviews (e.g. Fontes and O’Mahony, 2008) and we attempted to secure interviews with women and men teachers, particularly in Dadaab, remotely over mobile phones and using WhatsApp. These efforts were unsuccessful.

Finally, we conducted semi-structured interviews with 14 Kenyan national and international instructors in Kenya and Canada. The purpose of interviews with instructors was to surface perspectives on the evolution, implementation, and potential of instant messaging from those who created teacher training curriculum and coordinated teacher training programs (Lewis, 2003, p. 58). These questions included consideration for gender equity such as asking about where women's participation was visible, how gender-based power dynamics related to the curriculum and pedagogy or how gender dynamics surfaced across refugee teachers in chat groups. We refer to women and men who participated in interviews, both individual interviews and group interviews, as 'participants.' Table 1 provides an overview of data collection and methods.

[insert Table 1 around here] 
We engaged in a process of thematic coding of all interview data (both individual and group), starting with two of four researchers coding the same five transcripts and engaging in an iterative process of refining codes until we came to consensus about their definitions and application. All four team members reviewed the initial five coded transcripts and the entire team built out the final codebook before two researchers coded the full data set. The team reviewed all transcripts and discussed any final points of tension or divergence from the codebook. Our thematic coding surfaced interrelated findings at the global level between teacher training program instructors and refugee teachers (vertical) and at the local level among teachers in the camps (horizontal) (codebook themes are summarized in Appendix A).

In our survey data, we disaggregated by gender (M/F), self-identified by respondents, and analyzed comparatively across questions about general use of IM to communicate and IM used to communicate related to teacher training. There was one substantive open-ended question, which we coded thematically following the same code structure as for interviews. In addition, using simple linear regressions, we assessed the relationship between continuous variables and, using independent sample t-tests, compared the means of separate groups.

\section{SMS and IM use among refugee teachers: Survey findings}

Survey findings show that 199 out of 203 respondents had their own mobile phone across both locations, including all 40 women respondents. As shown in Table 3, Facebook Messenger, SMS, and WhatsApp were all marked as the most used applications for texting, and the affordances of the favored applications were listed as related to speed of communication, low cost, and rapid response times. Respondents identified mobile phones as the most used device to support their teacher training, with tablets and computers at school or work a far second, 
illuminating the important role of mobile phones and text-based applications for refugee teacher communities in camps. Most respondents used text messaging in the early morning before work or school, during lunch or breaks during the workday, afterschool, and in the evenings at home, with similar usage patterns for men and women. Our interview data, presented later, illuminate implications of this use for women and women's work in the home. Few respondents indicated using text messaging in class 'in real time' either as a learner in post-secondary classes or as a teacher in primary or secondary classrooms. Respondents also noted that they had the ability to receive and produce audio-video content on their mobile phones and that they did use these features, with the strongest response noting that respondents took and received photos as part of their chat groups to support their teacher training and ongoing professional development. Access to and use of photos over chat groups with other teachers was equally strong in women's responses.

[insert Table 2 around here]

When we asked respondents to denote use of SMS or instant messaging (IM) for types of communication, responses showed that they use SMS to communicate with classmates, colleagues, friends, and family in the camps. When asked about usage to support teacher training specifically, respondents noted high use of IM among teacher peers in the camps. When asking specifically about communication with internationally-situated instructors who may have taught in person in the camps first and then continued to engage remotely, or who may have only ever interacted with respondents online over instant messaging groups, email, and other digital tools, responses were different than for peer-to-peer communication. IM communication with 
internationally-situated instructors was marked as used more than SMS, but communication with instructors was still less than with peer networks.

This sample ( $\mathrm{N}=203)$ also allowed for the calculation of both simple linear regression and independent-sample t-test. ${ }^{1}$ We find a small gender effect (see Appendix C for full results) with women respondents slightly more likely to use messaging apps to talk to an instructor $(\mathrm{p}=0.002)$ and to ask and answer questions about their teacher training programs $(p=0.005)$ than men. This latter finding points to the significant role of mobiles in the professional pursuits of women refugee teachers (see Appendix C). Interview findings offer a more detailed view of how text and instant messaging are used among refugee teachers in the Kakuma Refugee Camps and across refugee teachers and international instructors in both Kakuma and Dadaab.

\section{Vertical and horizontal communication: Interview findings}

In this section, we present our findings considering the vertical and horizontal axes of inquiry (Bartlett, 2014). We frame our discussion of findings in relation to (1) vertical communication and relationships between refugee teachers and international instructors and (2) peer-to-peer or horizontal usage of text and instant messaging, considering locations and direction of power across these axes. We separate these analyses to emphasize that they are distinct and to address often overlooked differences in how the tool is used internationally and across the hierarchical structures of formal teacher training programs compared to more emergent and organic uses at the peer-to-peer level among refugee teachers in camps.

\footnotetext{
${ }^{1}$ All statistical power calculations for t-tests and regressions are over 0.99 for medium and larger effect sizes, considering $\mathrm{N}=203$.
} 


\section{Transnational teacher training: Vertical communications and relationships}

Building in the use of WhatsApp was essential to some instructors who saw it as a window into the lives of refugee teachers in camps and an ongoing opportunity to connect with them and share resources. Our interview findings indicate that international instructors often started out with more typical online and blended learning tools like email, or in some cases used SMS to send out one-way mass texts with administrative information about a course (e.g. upcoming deadlines). Our research suggests that they learned about and adopted the use of text messaging and instant messaging chats as they engaged in this work and following the lead of refugee teachers in Dadaab and Kakuma. Instructors who did use WhatsApp were from Canadian universities and described it as an opportunity to create more of a 'personal touch' online and as an opportunity to share materials with people who missed in-class sessions. The one author of this paper who also served as an instructor has reflected on the intentional use of SMS and WhatsApp among her BHER colleagues since the time of this data collection and noted it as an effort to provide refugee women teachers enrolled in teacher training programs opportunities to follow along with the content covered each week even if sometimes absent from class, to participate in online discussions, and to communicate directly and sometimes privately with instructors for help. Similarly, Instructor 3 described how technology helped mitigate absences and interruptions in a blended part-online, part-onsite program in Dadaab, saying: ‘[We used WhatsApp] straight through, because there were again the aspects of expectations, clarifying expectations, passing of documents to them. 'I didn't get that from the class today I was absent,' I went to claim my food rations, my brother is dying' (Instructor 3, June 3, 2016, Canada). For women students, these types of tasks often involved tending to the needs of their children and other forms of domestic labor. 
For international instructors, the use of WhatsApp chat groups was described as being quite time consuming, laborious, and uncertain with regard to who is and is not participating, as well as being challenging with regard to managing the influx of messages day and night, inconsistent networks in the camps, and maintaining longevity of the groups. Refugee teachers also sometimes described high volumes of communication but indicated a practice of simply skipping over those they missed. The responsibilities of being the instructor in charge of the course may make the process of quick-reading or skipping chat content- employed by refugee teachers - difficult because of expectations to manage the course and track and support student participation.

Considering the shift in workflow using mobile technologies, international instructors identified a challenge with regard to retaining information exchanged over these platforms, where information can amass and archiving and searching may be less clear than through tools more typically used in education like email and word processing. These material realities in the common practice of education, where resources are available, make the switch to mobile communication and the use of group chat difficult for instructors - particularly across expansive geographical and cultural barriers. Refugee teachers indicated scanning and reading through messages when they had time and when they wanted to, signaling less of a requirement or responsibility and more of a willing engagement and interest to read (or skip) certain messages and chats. With this in mind, Instructor 3 also described the 'danger of disappearing in the cracks' if participating refugee teachers do not have good mobiles or are not engaged continuously in the chat group and considering how much work it is for instructors to maintain and follow these conversations (Instructor 3, June 3, 2016, Canada). Several instructors saw some students participating more than others and observed gender divisions, with women 
participating less than men. Other instructors as well as refugee teachers identified instances where a few students would disseminate information to some peers, but not to those who were not so tightly connected to the online network - whether and how face-to-face communication happened between men and women refugee teachers is unclear. In this case, there is a challenge to virtual classroom management, in the immateriality of the virtual room and the refugee teachers remotely participating in chat groups there, leaving instructors feeling overwhelmed and sometimes unable to see engagement of refugee teachers, including women. This tension, related to social cohesion between peers and across the transnational instructor network, presents both challenges and opportunities for using WhatsApp to support formal, transnational teacher training programs.

\section{Amplifying in-service teacher training: Horizontal communications and relationships}

A critical finding of our study relates to the unexpected ways refugee teachers described their use of chat groups horizontally, across teacher communities in Kakuma. Where teachers learned about inclusive and critical pedagogical philosophies and teaching practices through their BHER and KEEP programs, the adoption and implementation of these lessons in practice were supported by peer-to-peer networks mediated over group chats and sometimes SMS. Importantly, mobile phone-enabled instant messaging chat groups created opportunities for teachers to overcome the limitations of participating in peer-to-peer professional development in an environment where physical movement across schools and camp settings is difficult and dangerous. Interviews with refugee teachers demonstrate ample peer-to-peer learning interests and contributions and the use of the mobile phone as an amplifying tool for these existing sociocultural capacities and motivations. Jonas, whom we introduced at the start of the paper, 
identified the ongoing work of teaching and supporting girls' education in the camps, and the role IM can play horizontally:

Actually, there was a situation which by some of our learners, two girls, had fought in the classroom....It happened during the evening and so the girls were not in the school. So we discussed that overnight [using WhatsApp] and in the morning we called those girls and we solved that problem. (Jonas, Group Interview 1, April 2016)

Group chats that emerged at a peer-to-peer level were built out of existing social practices of collaboration and collegiality; they enhanced opportunities for teachers to work together and fulfill their interests to foster community engagement and growth across camps. For example, WhatsApp group chats allowed for teachers to engage in inter-school activities in a setting where this would otherwise be difficult, due to the restrictions and arduous realities of moving across the vast region of Kakuma. One teacher described a cross-school competition where one school was dominating in their achievements and success, causing tension among the girls in the different schools: 'We put that [problem] in the WhatsApp group and the teachers discussed [it] and they visited the school that was defeated to encourage them and make them feel it was still part of bringing us together and not hatred.' (Refugee Teacher 4, Group Interview 4, Kakuma, April 2016).

Throughout these interviews, we find a confluence of 'professional' and 'social' engagements over group chats and to support girls' education. For example, one teacher described using WhatsApp groups for emotional and professional support at the end of a hard day: 'So for them [the teachers] they find that group help is social/emotional. For example, you had a hectic day in the field or you had a bad moment. When you share your moment with the 
group, you find those who will give you some form of relief...' (Refugee Teacher 2, Group Interview 3, Kakuma, April 2016). In addition, refugee teachers also used SMS and group chats more instrumentally as related to their work as teachers, to communicate with each other about sick days (administrative), ask permission for something from their head teachers, coordinate and plan activities in or across schools, and to troubleshoot social and pedagogical problems in the classroom and in the community related to school. One-to-one communication often used SMS, and teachers also used their phones to search for information using Google, do sums with the calculator, take photos, and record audio. Several teachers described using Google on their mobiles to search for information during class time, one pretending to take a call to use his phone in real time without exposing what he described as a lack of knowledge to the class.

WhatsApp groups were also used to engage the broader community, and particularly male community members, to support girls' education in Kakuma. While this element of the KEEP program in Kakuma was known to the research team at the outset of our study, we were surprised to learn about the significant role WhatsApp chat groups played. We highlight this finding as a connection point across horizontal and vertical axes, where the content of the community outreach activities was provided by the international teacher training program, coordinated by an international nonprofit organization, and facilitated by Kenyan instructors who flew into Kakuma to train refugee teachers. The refugee teachers were then tasked with implementing the gender equity initiative and instant messaging chat groups were often created organically by the refugee teachers involved. In this example, the refugee teachers and community educators talked to fathers and brothers about gender equity for the girls in their families. The men were then invited to a WhatsApp group to discuss early marriage before a 
face-to-face workshop and tasked with engaging others in these conversations. One refugee teacher explained:

Then we had a topic where we said is it good to marry a girl at early age or is it good for a girl to get pregnant before she finishes high school? So some men came up and said no, others were saying yes. Those who said yes we asked them why? 'So assume this is your daughter, this one has gone to school and this has not gone to school—-then we have men who have gone to school and those who have not gone to school. Who will you prefer to marry your daughter? The literate or illiterate?’ And then you find most of the men will prefer the literate. Then you tell [them:] if you need a literate person then you have to let your daughter go to school. Laughter. (Refugee Teacher 5, Group Interview 3, Kakuma, April 2016)

WhatsApp group chats do not replace face-to-face engagements around this topic, as several refugee teachers also described the importance of face-to-face discussions and direct community engagement. These chat groups do, however, play a critical role in the process of involving men in conversations about the importance of girls going to school continuously, nurturing opportunities for ongoing conversations in a setting where physical meetings with teachers who are trained in gender responsive pedagogy is limited. Importantly, gender equity is nurtured at the will of refugee teachers using the lessons they learned through international teacher training programs. We find that teachers take what they learn in these courses about gender equity and use instant messaging chat groups to further conversations across local community members. While this kind of outreach and community engagement may be part of certain initiatives, such as in KEEP, we found that the use of mobile based chat groups was largely organic or emergent 
among the participating refugee teachers rather than determined or coordinated by the transnational community of instructors involved in this landscape.

\section{Technology, teacher training, and gender equity}

In this work, we identify how amplification is demonstrated in refugee teachers' uptake of both the lessons learned through the transnational community of international instructors and programs supporting their in-camp work, where technology creates a channel for refugee teachers to expand their existing social networks and extend their intra-regional engagements beyond the physical boundaries of the camps and schools. Importantly, the use of SMS and instant messaging supports initiatives focused on changing the cultural landscape of gender equity in education in the camps, a distinctly feminist and sociotechnical interaction that perhaps surprisingly is often facilitated by men refugee teachers where there are far fewer women refugee teachers. It is unclear to us how women refugee teachers are affected by their engagement in these chat groups and local activities in terms of potential social and cultural changes pursuant from internationally-informed teacher training programs.

From a feminist perspective, we also consider the relationships between time, labor, and place-based mobility for women. Jonas, in fact, explained that he would leave his phone at home during school hours and consult group chats and other available resources in the evenings. Some participants indicated that they wanted to engage in thoughtful and meaningful work conversations with colleagues outside of work/school hours. Women in refugee camps in Kenya, however, have less leisure and at-home time to catch up on and participate in chat groups (Dahya \& Dryden-Peterson, 2017); and yet, women also used this at-home time, according to our survey, to participate in group chats related to teacher training. What does this mean for how women's 
time is divided, structured, and imposed upon? Does the use of this tool risk leaving women further behind if they can't keep up, add to their labor, or impart more demands on their time? The paradoxical nature of digital technologies’ ability to connect and fragment time, learning, and relationships permeates refugee teachers' lives as it does the lives of instructors internationally (see Wajcman, 2016). The differences and similarities in the experiences of international instructors and refugee teachers contributes to better understand a transnational social, material, and feminist perspective related to the use of mobile technology to support gender equity and refugee teacher training.

Our findings also contribute to understanding how transnational communities with a shared goal and focus (e.g. teacher training and gender equity in refugee camps) can use instant messaging chat groups to teach across the boundaries of camp borders as well as nation-states. In a context where people are geographically immobilized, and where other forms of technology, such as computer labs, are hard to access, mobile phones are a significant resource. We find that when Internet service goes down, community members call and use SMS to connect with each other, communicate about their teacher training programs, and collectively problem-solve teaching challenges. This flexible function is crucial as social, emotional, academic, and professional support overlap in Dadaab and Kakuma. The availability of these kinds of communications allow teachers to grow in their work and feel supported when they are most in need, largely through peer networks within their local communities, and also with room for expanding transnational learning and communication. In line with amplification theory, the effects of IM in these contexts connect to the preexisting social and cultural practices related to teacher training and social networks, including persistent pressure from local and international communities to enhance education in the camps for girls. 
Material ownership of a mobile phone supports virtual transnational group chats on IM, and these in turn inform and interrupt social practices and cultural norms in support of girls going to school and potentially for women teachers in Dadaab and Kakuma. In this landscape, knowledge related to the practice of teaching is shared transnationally and local teacher communities reconstruct their teaching and learning practices, shifting gender norms and practices along the way. Yet, there are gaps and questions related to those who are not part of these conversations, and to the further inclusion of women refugee teachers and others without access to even the basic material artifact of a mobile phone, or the technological literacy to use it for transnational group chat communication. We are left asking how to engage with dynamics of power and in/equity circulating across these transnational channels, to foster grounded, material changes that will protect and support girls and women teaching and learning in refugee camps. 


\section{Acknowledgements}

This work would not have been possible without the generous participation of teachers in Dadaab and Kakuma and the international instructors who shared their experiences with us, World University Service of Canada, Dr. Josephine Gitome and her team at Kenyatta University who facilitated research permits and data collection in Dadaab, and sponsorship from the University of Washington Royalty Research Fund.

\section{Funding}

This study was generously funded by the University of Washington Royalty Research Fund.

\section{References}

Bartlett, L. (2014). Vertical Case Studies and the Challenges of Culture, Context and Comparison. Comparative Education, 16(2), 30-33

Bartlett, L. \& Vavrus, F. (2017). Rethinking case study research: A comparative approach. New York, NY: Routledge.

Basch, L., Schiller, N.G., \& Blanc, C.S (1994). Nations unbound: transnational projects, postcolonial predicaments, and deterritorialized nation-states. London: Routledge.

Boskic, N., Sork, T.J., Irwin, R., Nashon, S., Nicol, C., Meyer, K., \& Hu, S. (2018). Using technology to provide higher education for refugees. In E. Jean-Francois (Ed.), Transnational perspectives on innovation in teaching and learning technologies. (pp. 285-304). Boston, MA: Brill.

Creswell, J. W. (2014). Research design: Qualitative, quantitative, and mixed methods approaches (4th ed.). Thousand Oaks, CA: SAGE Publications.

Dahya, N. \& Dryden-Peterson, S. (2017). Tracing pathways to higher education for refugees: the role of virtual support networks and mobile phones for women in refugee camps. Comparative Education, 53(2), 284-301. http://dx.doi.org/10.1080/03050068.2016.1259877

Dryden-Peterson, S., Dahya, N. \& Adelman, E. (2017). Pathways to educational success among refugees: Connecting locally and globally-situated resources. American Educational Research Journal, 54(6), 1011-1047. http://journals.sagepub.com/doi/abs/10.3102/0002831217714321

Fontes, T.O. \& O’Mahony, M. (2008). In-depth Interviewing by Instant Messaging. Social Research Update. Issue 53. University of Surrey, United Kingdom.

Leung, L. (2018). Technologies of refuge and displacement. Lanham, MD: Lexington Books.

Lewis, J. (2003). Design Issues. In J. Ritchie \& J. Lewis (Eds.), Qualitative research practice: A guide for social science students and researchers (pp. 47-77). London: SAGE, 
Ling, R. \& Horst, H. (2011). Mobile communication in the global south. New Media \& Society, 13(3), 363-374. DOI: 10.1177/1461444810393899

Mendenhall, M., Gomez S., \& Varni E. (2018). Teaching amidst conflict and displacement: persistent challenges and promising practices for refugee, internally displaced and national teacher. Paper commissioned for the 2019 Global Education Monitoring Report; Migration, displacement and education: Building bridges, not walls. Retrieved from UNESCO Digital Library: https://unesdoc.unesco.org/ark:/48223/pf0000266060

Pimmer, C., Zelezny-Green, R., \& Gröhbiel, U. (2018). A lifeline to learning: Leveraging technology to support education for refugees. F. Miao, M. Pagano, \& M. West (Eds.). Retrieved from UNESCO website: http://unesdoc.unesco.org/images/0026/002612/261278e.pdf

Roudometof, V. (2005). Transnationalism and cosmopolitanism: errors of globalism. In R.P. Appelbaum and W.I. Robinson (Eds.). Critical globalization studies (pp. 65-74). New York, NY: Routledge.

Toukan, E.V., Gaztambide-Fernández, R., \& Anwaruddin, S.M. (2017). Shifting borders and sinking ships: What (and who) is transnationalism "good" for? Curriculum Inquiry, 47(1), 113. DOI: $10.1080 / 03626784.2017 .1281049$

Toyama, K. (2011, February). Technology as amplifier in International Development. In Proceedings of the 2011 iConference (pp. 75-82). Seattle, WA.

Toyama, K. (2015). Geek heresy: Rescuing social change from the cult of technology. New York, NY: Public Affairs.

UN High Commission for Refugees. (2016). Connecting refugees: How internet and mobile connectivity can improve refugee well-being and transform humanitarian action. Retrieved from UNHCR website: http://www.unhcr.org/5770d43c4.pdf

Unwin, T., Weber, M., Brugha, M., and Hollow, D. (2018). A report from Save the Children: The future of learning and technology in deprived contexts. Retrieved from the Save the Children website:

https://resourcecentre.savethechildren.net/node/13074/pdf/the_future_of_learning_and_techno logy.pdf

Wajcman, J. (2006). Feminization of work in the information age. In M. F. Fox, D. G. Johnson, and S. V. Rosser (Eds.), Women, gender, and technology (pp. 80-96). Urbana, IL: University of Illinois Press.

Wajcman, J. (2016). Pressed for time: The acceleration of life in digital capitalism. Chicago, IL: University of Chicago Press. 
Witteborn, S. (2018). The digital force in forced migration: imagined affordances and gendered practices. Popular Communication, 16(1), 21-31. 